\title{
Biosolids Management in Circular Economy: Lessons from around the World
}

\author{
Banu Örmeci \\ Carleton University, Canada
}

Biosolids treatment and management is a growing challenge for treatment plants globally. The cost of biosolids treatment constitutes to approximately half of the cost of wastewater treatment, and the quantities increase as new wastewater treatment facilities are built and the existing ones are upgraded to keep up with the growing population and stricter regulations that require advanced treatment.

Unlike linear economy that was built on the "take, make and dispose" philosophy, circular economy emphasizes recovering and reusing resources as long as possible. The circular economy concept and its application to biosolids treatment and management has immensely helped to advance the science, research and technology in achieving recovery of nutrients, energy, carbon, and bioproducts from sludge. The European Commission implemented the Closing the loop - an EU Action Plan for the Circular Economy in 2015 and several other countries are now in the process of implementing similar action plans including Canada (e.g., Ontario's new Strategy for a Waste-Free Ontario: Building the Circular Economy).

Prof. Banu Örmeci is the Chair of the International Water Association (IWA) Specialist Group on Sludge Management which has members from 120 countries. In this presentation, she will share how circular economy is interpreted and implemented in Europe, Australia and Asia, and successful applications and approaches that can also be adopted in North America. These will include new and novel methods for energy and nutrient recovery; source control of emerging contaminants, nanoparticles and microplastics; control measures for pathogens and antibiotic resistant bacteria, and beneficial use of biosolids. The rapidly changing regulatory environment will also be covered including recent bans in Europe on land application of biosolids. 